\title{
Fire in Orbit: \\ Equipping the Commercial Spaceflight Industry for Fighting Fire in Micro-Gravity
}

\author{
Trent Cybela ${ }^{1}$ \\ Orbital Technologies Corporation, Madison WI \\ University of Wisconsin - Platteville, Platteville WI
}

List of Terms
\begin{tabular}{|l|l|}
\hline CCiCap & Commercial Crew Integrated Capability \\
\hline ECLSS & Environmental Control and Life Support System \\
\hline EVA & Extra-Vehicular Activity \\
\hline FWM & Fine Water Mist \\
\hline ISS & International Space Station \\
\hline LEO & Low Earth Orbit \\
\hline PFE & Portable Fire Extinguisher \\
\hline UHPFE & Ultra High Pressure Fire Extinguisher \\
\hline USOS & United States Orbital Segment \\
\hline
\end{tabular}

\begin{abstract}
For several years, Orbital Technologies (ORBITEC) has had keen interest in the development of a portable fire suppression system intended for use in commercial spaceflight applications. With the aid of recent developments in fine water mist (FWM) atomization technologies, and partnerships with the University of Wisconsin - Platteville, work is commencing to develop a portable fire extinguisher (PFE). The extinguisher will be capable of operation in both gravity and microgravity environments regardless of orientation, and eliminate the use of toxic carbon dioxide as a fluid suppressant. The extinguisher will take advantage of the unique physics of microgravity to better suppress fires compared to previously used equipment. The following report outlines baseline research into the historical precedence of spacecraft fires, and common modes of fire ignition in microgravity. From this information we investigate design considerations necessary for the construction of a prototype PFE, as well as the market value of such a device.
\end{abstract}

\section{Introduction}

In the design of new space habitats and vehicles, considerations for the prevention and suppression of fires must be made. As far back as the Mercury and Gemini missions, astronauts had at their disposal various methods by which to extinguish fires (Friedman, 1999). PFE technology used today onboard the ISS is outdated, expensive, and not conducive for investment by the commercial spaceflight industry. Advances in fire suppression technology can be applied to new PFE systems which are effective at eliminating many common microgravity fire threats while being cost effective, lightweight, and portable. ORBITEC stands at a position currently to leverage industry experience towards creating a new PFE system for microgravity environments. In order to move forward, a strong foundation must be established in the history, causes, and current methods used to extinguish fires in space. This report follows the research phase of the

\footnotetext{
${ }^{1}$ Special thanks to the Wisconsin Space Grant Consortium (WSGC) who provided the necessary funding for student involvement in this project.
} 
project, with commentary describing our intentions for the design and prototyping of the PFE. A first-level prototype is on schedule for completion before year's end, 2014.

\section{Fire Science Overview}

There are three elements required for a combustion reaction to take place: a fuel source, oxidizer, and heat energy. Removal of just one of these three elements will cause a fire to collapse. Most portable fire suppression systems focus on the removal of the oxidizer or heat energy from the combustion system. This is done because removing the fuel source after the advent of a fire is typically not practical. The three components required for combustion are the same both on earth and in space. The behavior of fire in microgravity however, is different compared to earth.

The "teardrop" shape of a candle flame does not occur in orbit. On Earth, the flame's shape is defined by the effects of gravity: the buoyancy of hot gases and movement of convection currents. Without gravity fire takes a much more spherical shape, as shown in Figure 1. There is no natural convection in microgravity. In the absence of an upward direction for a fire to burn, it burns in all directions. Typically microgravity fires burns slower as well; mainly because flames tend to be weaker without the aid of convection currents. New oxygen is not "swept" into the fire but needs to diffuse into the combustion area, which takes more time to accomplish (Friedman, 1999). Fires in space:

1. Burn at slower rates

2. Burn at lower temperatures, requiring less heat energy

3. Burn at lower oxygen levels, using 2-3\% less oxygen compared to earth.

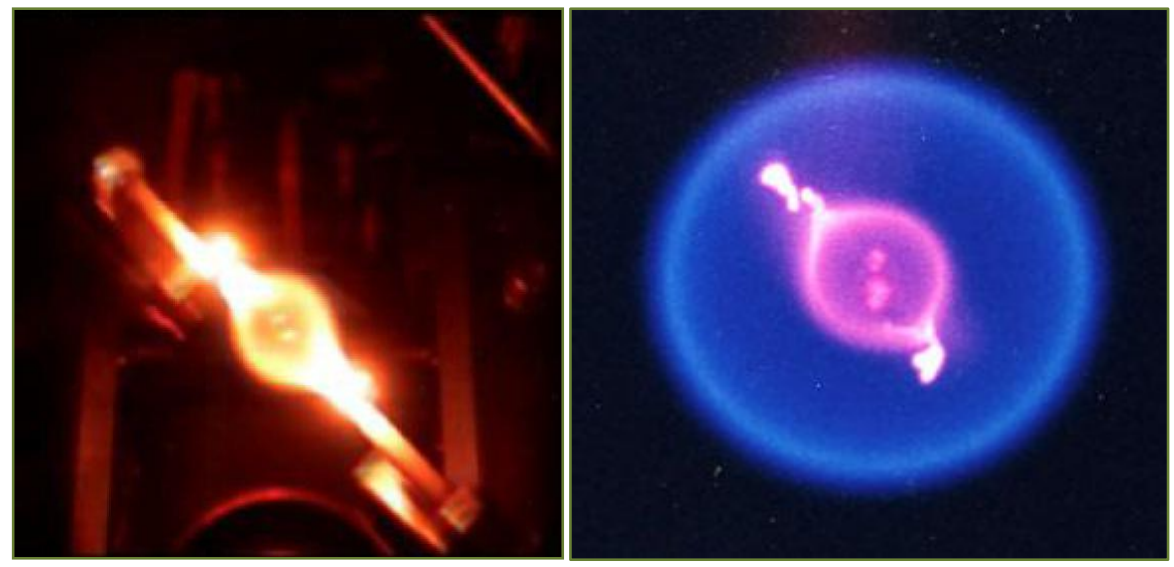

Figure 1: N-Heptane burning in micro-gravity, Credit: NASA.

These factors mentioned, fire in space can be both harder to detect and more persistent. Although we had previously mentioned the absence of natural convection in microgravity, there are other methods of airflow which occur in these environments. Human spaceflight requires ventilation systems to circulate and filter the enclosed atmosphere. These systems can be very effective at moving large volumes of gas and vapors over short periods of time. The ISS - having a pressurized internal volume of 388 cubic meters - could easily circulate smoke and harmful gases through the entire station in less than a half hour period (McKinnie, 1997). Additionally, 
airflow from the ventilation system has the ability to stoke potential fires, or give direction and speed to fires that already have started to burn.

\section{Historical Overview}

Over the course of 30 years from 1967 to 1997 there have been a least seven recorded incidents of fire onboard spacecraft and space stations (Barr, 2010; Sanchez, 2000). Figure 2 gives a timeline of incidents along with the specific craft involved (red crosses denote loss of life or life threatening situation). Aside from the Apollo 1 fire in 1967 all incidents occurred during actual flight. The frequency of these incidents together with other risk assessment analysis led NASA to predict that over the lifespan of the ISS a minimum of two fires would occur on the station (McKinnie, 1997).

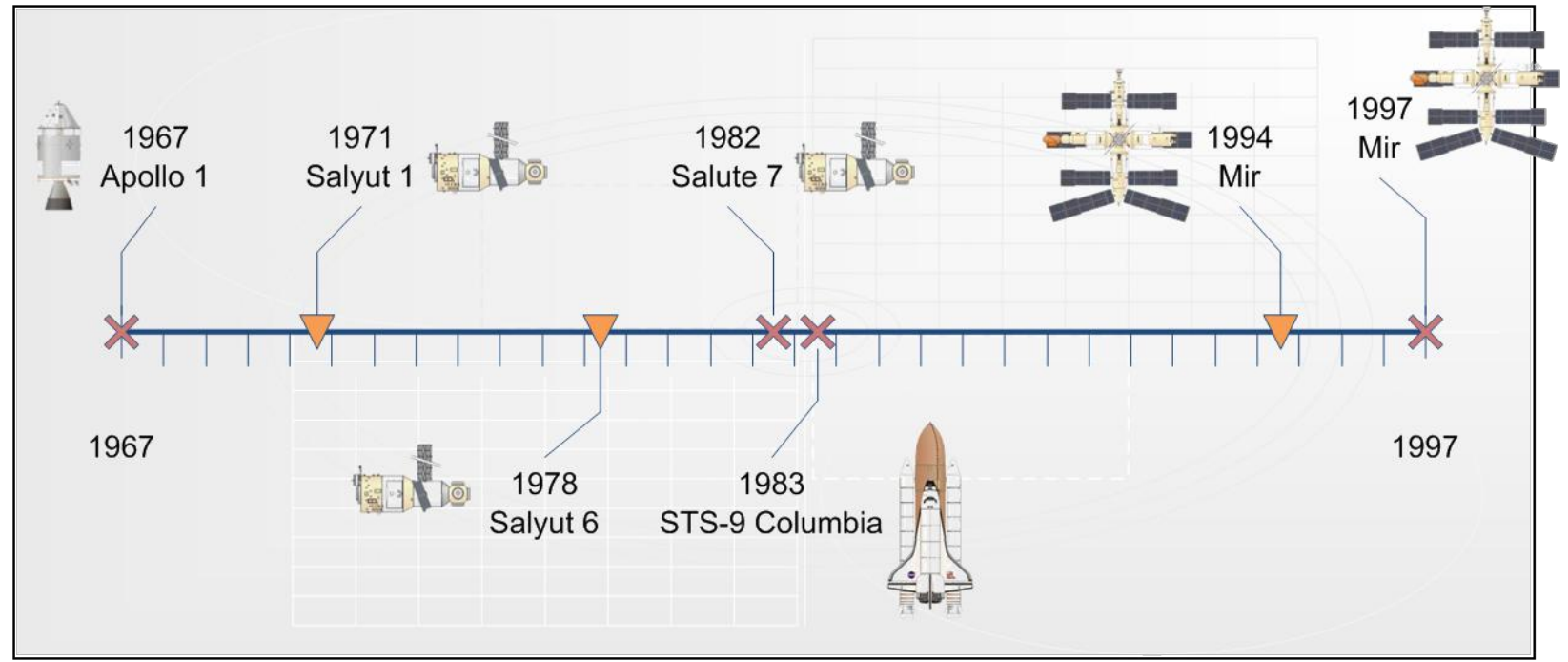

Figure 2: Timeline of fire occurrences. Red crosses denote life threatening situations.

The most serious of the orbital fires occurred on space station Mir. The station caught fire twice both in 1994 and 1997. The '97 event was the most serious, where a failure in one of two oxygen generation systems onboard caused a fire which burned for 15 minutes before finally selfextinguishing (Figure 3). The crew was not able to suppress the reaction because the foamingagents used in the station's PFEs were designed to blanket and suffocate fire. Because the system which had caught fire was designed to generate oxygen, blanketing the fire to eliminate oxygen was ineffective. The system created oxygen by burning what is commonly called "oxygen candles". Similar candles to those onboard the station are commonly used throughout the commercial airline industry to generate emergency oxygen for passengers. 


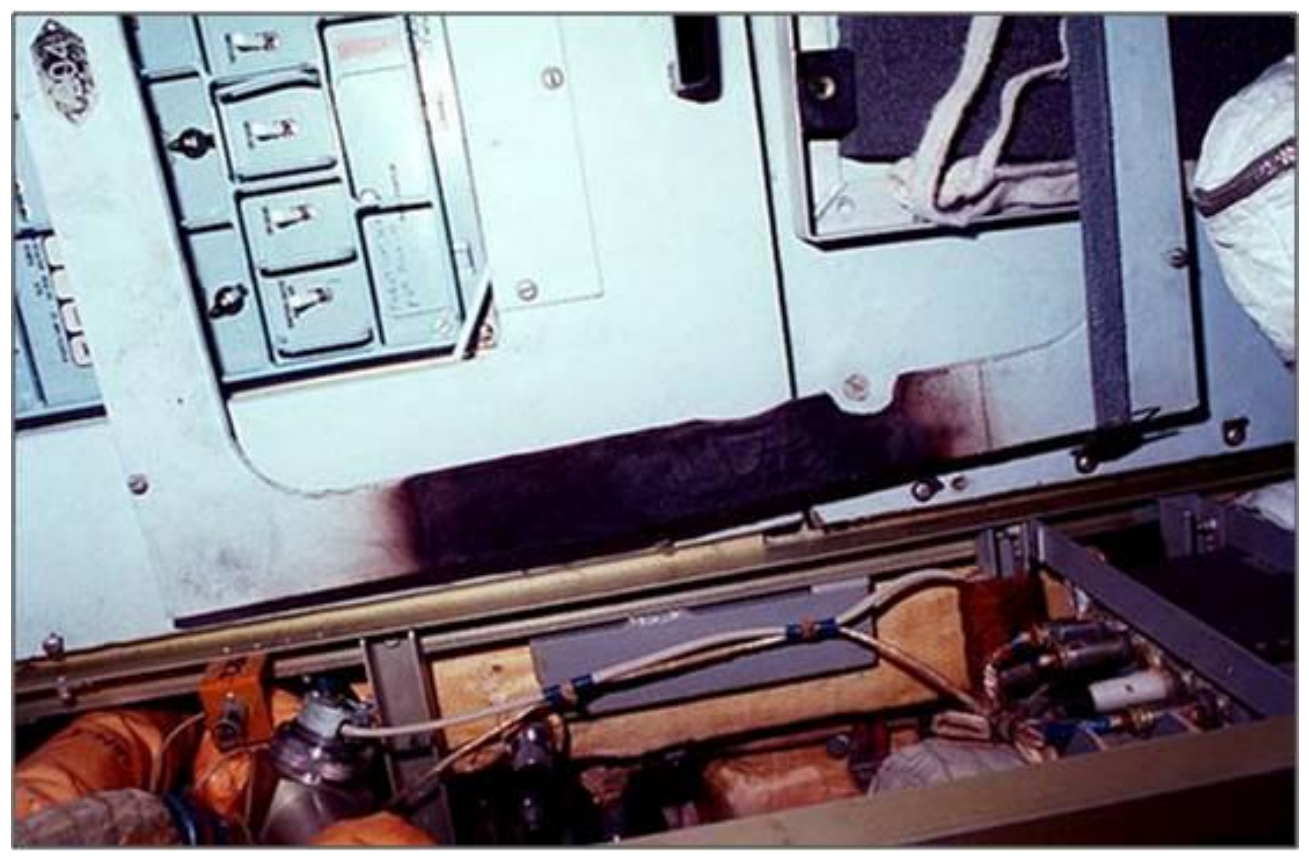

Figure 3: Fire-damaged panel onboard Mir, Credit: NASA.

\section{Fire Modes in Microgravity}

Fire is taken very seriously onboard the ISS. The USOS alone houses 13 fire extinguishers, and many studies have been done to determine the most likely causes of fire. Besides oxygen candles, various spaceflight applications (including astronaut EVAs) require elevated oxygen as part of the ambient atmosphere, which heightens the risk of fire. There is also growing concern regarding the amount of lithium-ion (Li-ion) batteries currently being used on the ISS in laptops and other electronics. Looking forward it is likely that commercial spaceflight will also rely heavily on these batteries. Recall when the Boeing's Dreamliner aircraft were grounded after fires involving Li-ion batteries. These batteries can also burn in the absence of atmospheric oxygen as well. This property eliminates one possible mode of defense against spacecraft fires, which would include depressurizing the cabin to remove the oxygen.

Liquid chemical fires are possible as well, although less likely to occur in habitable segments of a spacecraft. Hydrazine is a common fuel source for both power and propulsion in the space industry. A hydrazine leak from several of space shuttle Columbia's auxiliary power units caused a fire which could have crippled the craft's hydraulic systems needed for re-entry (Barr, 2010).

Historically through to the present, electrical fires have always been the biggest concern in regards to human spaceflight. Due to the size and volume constraints placed on Earth-launched vehicles, electrical wiring is typically packed as tight as possible inside a spacecraft. These wires are many times hidden away behind panels where it would be very difficult to visually identify the source of any smoldering or combustion taking place in the wire bundles. It is important to note that reaching the necessary heats for combustion is much easier in microgravity. Overheated motors, bearings, wires and other components will remain hot longer due to a lack of convective heat transfer in microgravity (Friedman, 1999).

\section{Current Systems}


The US orbital segment's PFE represents the most modern system currently available for space (Wieland, 1999). It is a compressed $\mathrm{C}_{2}$ extinguisher, designed to be discharged completely in the event of a fire over a 60 second period. A diagram of the PFE can be seen in Figure 4. It carries $6 \mathrm{lbs}(2.7 \mathrm{~kg})$ of $\mathrm{C}_{2}$ with a net weight of $12 \mathrm{lbs}(5.35 \mathrm{~kg})$. The discharge pressure is around $850 \mathrm{psi}(8.56 \mathrm{MPa})$. The design intent behind this device was the elimination of fires which cannot be directly observed, occurring behind electrical panels or inside experiment racks onboard the ISS. In many ways it is a brute force tool, meant to indiscriminately fill a large volume quickly and remove breathable air from the combustion reaction. For this reason it is also required for astronauts to use portable breathing equipment while operating the PFE, else they may be injured by the large concentrations of $\mathrm{CO}_{2}$. During operation, rapid expansion of the enclosed gas will cause the tank surface temperature to drop as low as -37 degrees C. Once the fire is extinguished the additional carbon dioxide is scrubbed by environmental controls, and excess pressure is vented from the cabin to space.

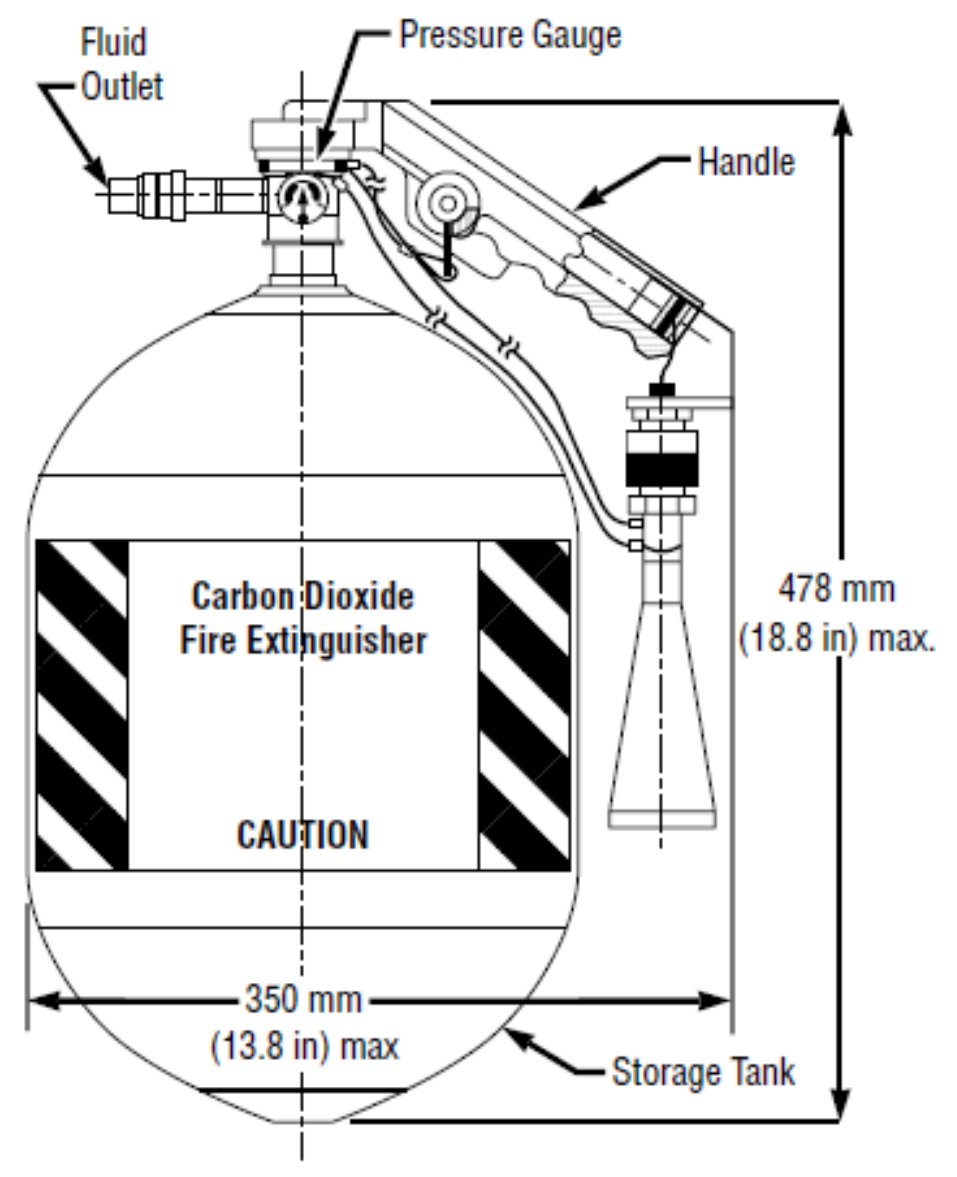

Figure 4: USOS PFE Diagram, Credit: NASA.

Analyses of the present options for space-application fire extinguishers lead us to conclude they are not acceptable for commercial spaceflight. For instance, they are far too expensive. The sales price for just one USOS unit is approximately one million dollars. They are also heavy, cannot be easily operated single-handed, and take up a large volume of usable storage space. A PFE suitable for commercial spaceflight needs to be highly mobile, effective at removing most if not 
all of the fire hazards previously discussed, and cost effective. This is why ORBITEC will develop a more acceptable alternative for spaceflight applications. Doing so will require several important decisions to be made regarding the function of the device. Mainly, the type of fluid used as a fire suppressant will need to be determined.

The use of gas as a suppressing fluid is a good choice for microgravity environments because of its ability to fill three-dimensional space. Liquid suppressants travelling through free space tend to "ball up" due to surface tension effects and wander around instead of canvassing the combustion event (Butz, Carriere, Abbud-Madrid, \& Easton, 2011) (Butz, Carriere, AbbudMadrid, \& Easton, 2011). Liquids however do have other properties which could apply very well to microgravity applications, provided the delivery mode is effective at concentrating the fluid to where the fire actually occurs.

\section{New Technologies}

Over the past decade studies have been conducted on the effectiveness of water-based fire suppression systems in microgravity. Studies led by researchers at the Colorado School of Mines used atomized water droplets to fight microgravity fires (Angel \& McKinnon, 2003). The findings from these studies have been subsequently applied to the development of delivery methods for these highly atomized droplets referred to as FWM (fine water mist) systems (Butz \& Abbud-Madrid, 2010). FWM allows liquid to behave in open areas like gases, operating threedimensionally and creating a dense fog rather than a continuous stream of fluid. This gas-like behavior is enhanced by the microgravity environment of a spacecraft.

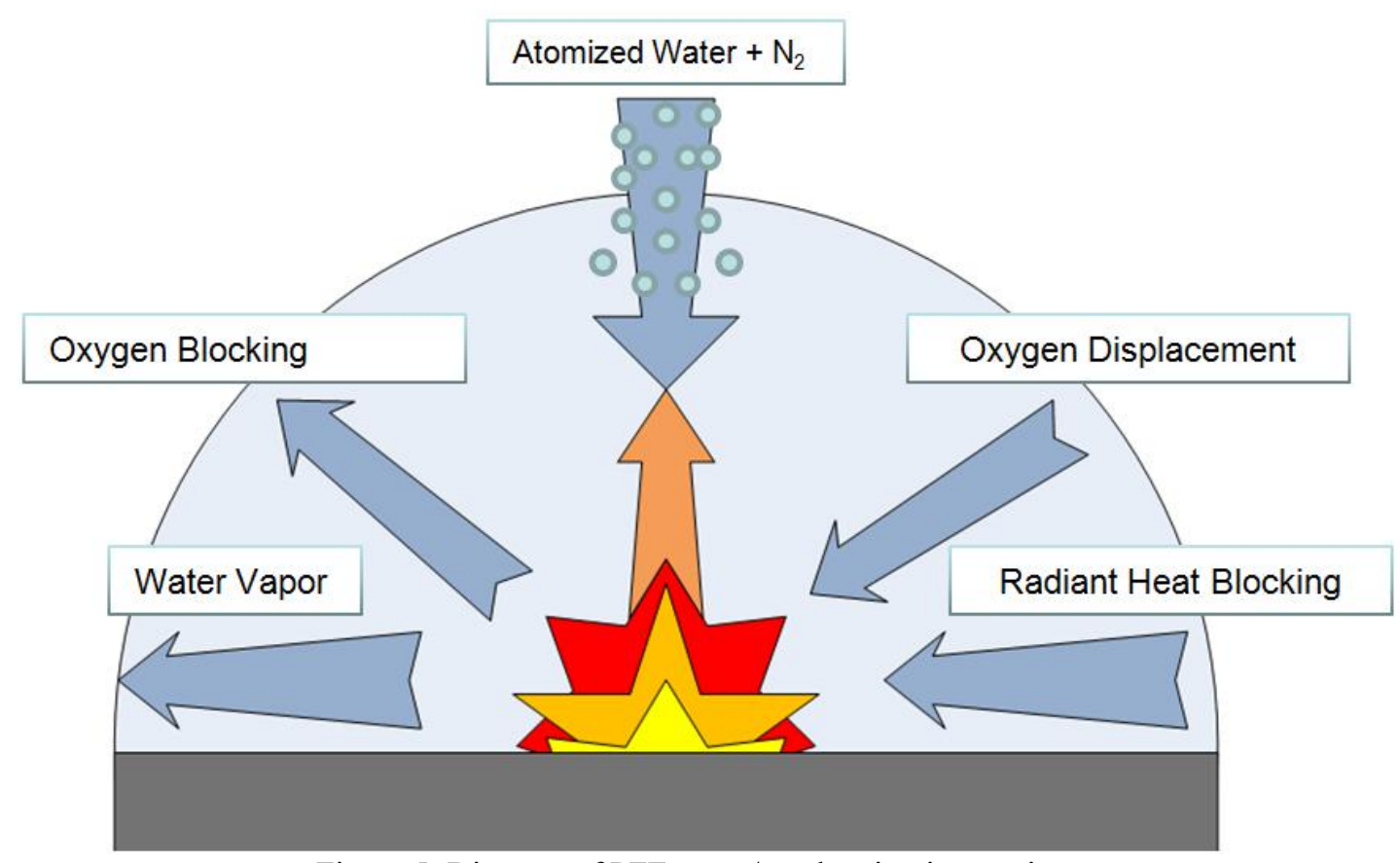

Figure 5: Diagram of PFE spray/combustion interaction.

Water has a very large latent heat capacity; meaning its ability to absorb heat energy is substantial. By delivering water to the fire as micron-sized droplets the liquid can readily absorb conducted and radiated heat, rapidly decreasing the thermal energy in the system below what is 
necessary for sustained combustion. As the water droplets begin to vaporize, the resulting steam displaces ambient oxygen to quicken the extinguishing process (Figure 5). The FWM valve assembly works to atomize the water droplets by mixing a continuous water stream with nitrogen (an inert gas) prior to expulsion from the nozzle (Figure 6). Under ultra high pressure (UHP), the nitrogen and water mix effervescently and travel in tandem towards the fire. By using compressed nitrogen as part of the PFE system, the mean diameter of the water droplets is reduced to sizes otherwise unobtainable using only mechanical fluid separation (Butz \& AbbudMadrid, 2010). The use of nitrogen also works to further reduce the amount of available oxygen in the combustion area. Research done onboard space shuttle Columbia in 2003 showed that water droplets between 20 and 50 microns in diameter were most effective at absorbing the heat energy of fire. This level of atomization is possible with the FWM system.

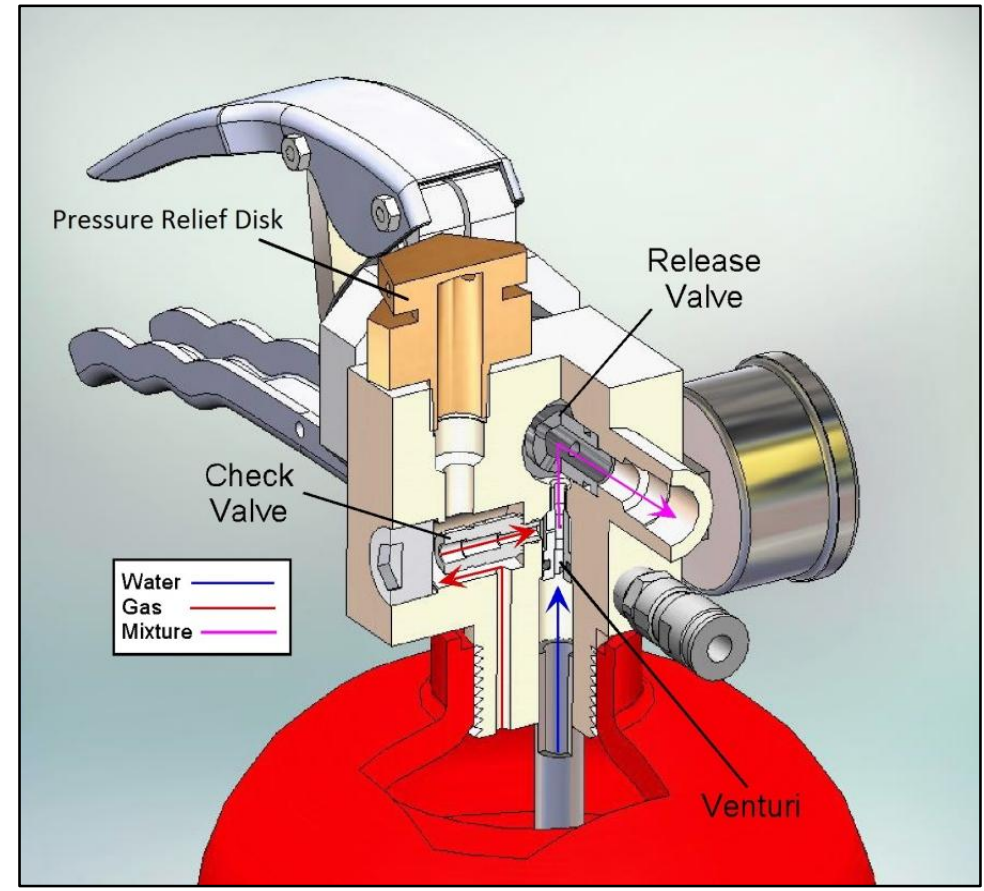

Figure 6: FWM PFE fluid flow path, Credit: ADA Technologies.

Because operation of the PFE will require the storage and pressurization of both nitrogen and water, a unique two-phase fluid management system must be developed for use with the FWM nozzle assembly. Leading design alternatives involve the use of an elastic bladder inserted into the PFE's tank. The water-filled bladder would be kept under pressure by compressed nitrogen which fills the remainder of the tank's volume. The tank and bladder assembly would need to withstand pressures in excess of 1000 psi for nominal atomization to take place.

Other alternatives to using bladders are possible. Another design would include taking advantage of the unique physics of micro-gravity and capillary-actions to deliver the fluids into the FWM assembly. This method would work without needing to physically separate the gas and liquid phases inside the tank, but would also make operation of the PFE under normal gravity much more difficult. 


\section{Future Markets}

The only other PFE currently under development for space is being championed by NASA as a possible replacement solution for the majority of $\mathrm{CO}_{2}$ extinguishers already on the ISS. Although the water atomization process for this extinguisher is similar to what has been described previously, this unit is far too massive and expensive for investment consideration by commercial spaceflight. This is why ORBITEC is looking into the development of a lightweight and cost effective prototype, which could be marketed to major aerospace companies. Boeing, SpaceX, and Sierra Nevada Corporation all are developing crew transport vehicles. Countless other companies are trying for the same goals without the aid of CCiCap funding. Any craft carrying humans will require auxiliary fire suppression capabilities in addition to standard ECLSS functions. At the current stage of development it is doubtful that any of these companies have a completely clear solution in regards to PFE integration. Additionally, the markets available to an environmentally friendly PFE with such unique operating features extend beyond the scope of LEO flight operations (perhaps even to ground-based "spin-off" products).

Vehicles which provide the opportunity for space tourism also need to consider fire protection. Virgin Galactic's space plane, SpaceShip Two is the current poster-child for space tourism ventures. Other companies are in the development of suborbital space planes, as well as other creative methods to bring citizens to the edge of space. World View Enterprises, a company from the American Southwest, plans to take passengers aboard a high altitude balloon to experience extremely high altitudes at a fraction of the cost of rockets.

Bigelow Aerospace is also an interesting opportunity. This company has been developing inflatable space habitats for over a decade, and in 2015 plans to attach an inflatable module (titled $B E A M$ ) to the ISS for further expansion of the station. They also are developing standalone private space stations using the same technology. Because their designs do inflate, venting the craft's internal atmosphere in an attempt to extinguish a fire becomes more problematic. Having a reliable PFE system to handle fire events would be very beneficial.

Although currently more loosely connected to microgravity fire suppression, companies including Planetary Resources and Deep Space Industries (DSI) would be interested in space PFE technology as well. These companies have long-term ambitions to develop the infrastructure needed for mining, refining, and manufacturing in places off-earth and beyond LEO. It goes without saying that wherever humans dare venture, fire will follow.

\section{Conclusion}

For any company looking to invest in commercial spaceflight, there will come a time when the issue of fire suppression needs to be addressed. As it stands, ORBITEC is an aerospace company with many products and systems already used in spaceflight applications. ORBITEC also happens to have significant experience in ultra high pressure fire suppression equipment, being the owner of HMA Fire Apparatus. Over the coming months, ORBITEC will continue to work with both university partners and the Wisconsin Space Grant Consortium (WSGC) to build, test, and validate ultra-high pressure portable fire extinguishers suitable for commercial spaceflight applications - with a first-level prototype ready for testing before the end of 2014. By building this PFE we will be closer to the creation of a great commercial product, which in turn will help protect the lives of astronauts. 


\section{References}

Angel, A.-M., \& McKinnon, J. T. (2003). Suppression of Premixed Flames by Water Mist in Microgravity: Findings from the MIST Experiment on STS-107. Golden: Colorado School of Mines.

Barr, S. (2010). Evaluating Failures and Near Misses in Human Spaceflight History for Lessons for Future Human Spaceflight. Houston: The Aerospace Corporation.

Butz, J. R., Tuchi, C. S., Kimball, A., McKinnon, T., \& Riedel, E. P. (2014). Patent No. 8746357 B2. United States of America.

Butz, J., Carriere, T., Abbud-Madrid, A., \& Easton, J. (2011). Zero Gravity Aircraft Testing of a Prototype Portable Fire Extinguisher for use in Spacecraft. International Association for the Advancement of Space Safety.

Friedman, R. (1999). Fire Safety in the Low-Gravity Spacecraft Environment. Cleveland: NASA Glenn Research Center.

Hickman, J. M., Dietrich, D. L., Hicks, M. C., Nayagam, V., \& Stocker, D. (2012). FLEX: A Decisive Step Forward in NASA's Combustion Research Program. 1st Annual International Space Station Research and Development (p. 21). Denver: American Astonautical Society.

Martin, C. E., \& Dalee, R. C. (1993). Spacecraft Fire Detection and Suppression (FDS) Systems: An Overview and Recommendations for Future Flights. Warrendale, PA: SAE.

McKinnie, J. M. (1997). Fire Response Aboard the International Space Station. Warrendale, PA: SAE.

Rodriguez, B., \& Young, G. (2013). Development of the International Space Station Fine Water Mist Portable Fire Extinguisher. American Institute of Aeronautics and Astronautics, 1-8.

Sanchez, M. J. (2000). A Human Factors Evaluations of a Methodology for Pressurized Crew Module Acceptability for Zero-Gravity Ingress of Spacecraft. Houston: NASA Johnson Space Center.

Smith, R. L., \& Kashiwagi, T. (1989). Expert Systems Applied to Spacecraft Fire Safety. Gaithersburg: National Institute of Sandards and Technology.

UCSD Jacobs. (2012, January 31). How Do You Fight Fire in Space? Experements Provide Some Answers. Retrieved June 30, 2014, from UCSD Jacobs School of Engineering:

http://www.jacobsschool.ucsd.edu/news/news_releases/release.sfe?id=1156

Wieland, P. O. (1999). Living Together in Space: The Design and Operation of the Life Support Systems on the Interantioal Space Station. Huntsville: NASA Marshall Space Flight Center.

Youngblood, W. W., \& Vedha-Nayagam, M. (1989). Advanced Spacecraft Fire Safety: Proposed Projects and Program Plan. Hunstville: Wyle Laboratories. 